\title{
Role of Defects in Photocatalytic Water Splitting: Monodoped vs Codoped $\mathrm{SrTiO}_{3}$
}

\author{
Manish Kumar,* Pooja Basera, Shikha Saini, and Saswata Bhattacharya* \\ Department of Physics, Indian Institute of Technology Delhi, New Delhi, India \\ E-mail: manish.kumar@physics.iitd.ac.in; saswata@physics.iitd.ac.in
}

Phone: +91-11-2659 1359. Fax: +91-11-2658 2037 


\begin{abstract}
Using the hybrid density functional theory and ab initio atomistic thermodynamics, we report monodoping of non-metal $(\mathrm{N})$ or metal $(\mathrm{Mn})$ in $\mathrm{SrTiO}_{3}$ can induce visible light absorption, but none of them are suitable to ameliorate the photocatalytic activity. Therefore, in order to achieve enhanced photocatalytic activity of $\mathrm{SrTiO}_{3}$, we have employed codoped $\mathrm{Mn}$ and $\mathrm{N}$ simultaneously in $\mathrm{SrTiO}_{3}$ to modulate its electronic properties effectively. In the codoped $\mathrm{SrTiO}_{3}$, the recombination of photogenerated charge carriers is suppressed, and the diffusion and mobility are increased owing to the passivation of discrete localized states. Our results reveal that $\mathrm{Mn}_{\mathrm{Sr}} \mathrm{N}_{\mathrm{O}}$ (codoping of $\mathrm{Mn}$ at $\mathrm{Sr}$ site and $\mathrm{N}$ at $\mathrm{O}$ site) is the most promising candidate for enhancing the photocatalytic activity of $\mathrm{SrTiO}_{3}$ under visible light.
\end{abstract}

\title{
Graphical TOC Entry
}

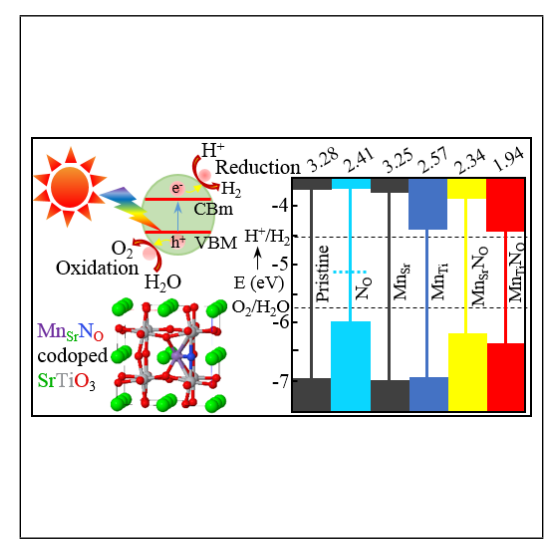




\section{Introduction}

$\mathrm{SrTiO}_{3}$ has emerged as one of the most promising energy materials ${ }^{1-5}$ for photocatalytic water splitting. ${ }^{6-12}$ However, owing to its large band gap $(3.25 \mathrm{eV}),{ }^{13}$ its application at a commercial level is delimited. Thus, several works have been endeavored to reduce the band gap of $\mathrm{SrTiO}_{3}$ in order to induce visible light absorption via doping with metals, ${ }^{14-18}$ nonmetals ${ }^{19-24}$ or combination of several elements. ${ }^{25-29}$ However, the band gap reduction cannot ensure the enhancement in photocatalytic efficiency as it also depends on the location of conduction band minimum $(\mathrm{CBm})$ and valence band maximum (VBM). For transition metal (TM) doped $\mathrm{SrTiO}_{3}$, TM d-states hybridize with those states of the $\mathrm{SrTiO}_{3}$ that contribute to conduction band, and thus, the reduction in band gap occurs by shifting of $\mathrm{CBm}$ in downward direction. However, due to this, the reducing power is deteriorated. Also, in general, doping by $3 \mathrm{~d}$ elements lead to localized states in the gap, which are detrimental to the photocatalysis. Therefore, transition metal alone is not suitable for improvement in photocatalytic activity. On the other hand, nonmetal doped $\mathrm{SrTiO}_{3}$ is found to narrow the band gap by elevating the VBM. But in this case also, localized states are appeared deep inside the forbidden region, which can trap the photoexcited charge carriers and accelerate the electron-hole recombination. This in turn degrades the photocatalytic efficiency. ${ }^{15,30}$ This has motivated us for codoping. The codoping with a metal is one of the pre-eminent solutions to passivate such discrete states of dopants in the forbidden region, and form the continuum band. ${ }^{30-33}$ By means of codoping, band edges can be engineered to comply with the needs, i.e., the spectral response expands to the visible region, while retaining the reduction and oxidation power. ${ }^{34,35}$ A thorough screening of the codopants has been done by calculating the band gap (see Table S1 in Supporting Information (SI)). From here, we have

identified few promising systems (marked as red) and one of them is the $\mathrm{N}$ and $\mathrm{Mn}$ codoped system. The decrement in band gap is most suitable for the Mn and N codoped system, whereas in rest of the cases, the band gap decrement is either larger or smaller than what is needed for the maximum efficiency in photocatalytic water splitting $\left(\sim 2 \mathrm{eV}^{36,37}\right)$. Moreover, 
one of the important factors for choosing $\mathrm{Mn}$ is that, it has d-d transition and its d-orbitals' energy facilitates the suitable potentials for water redox reactions. Note that the individual monodopants (i.e. $\mathrm{N}$ and $\mathrm{Mn}$ ) have already been experimentally synthesized. ${ }^{22,38-41}$ However, for the codoping of $\mathrm{Mn}$ and $\mathrm{N}$ in bulk $\mathrm{SrTiO}_{3}$, any experimental or theoretical reports are hitherto unknown.

In this article, we have, therefore, studied codoped (N-Mn) $\mathrm{SrTiO}_{3}$ for enhancing the photocatalytic efficiency under visible light. To understand the N-Mn codoped case, first we have addressed the respective monodoped (N, Mn) cases and their thermodynamic stability using hybrid density functional theory (DFT) ${ }^{42,43}$ and $a b$ initio atomistic thermodynamics at realistic conditions (temperature $(T)$, partial pressure of oxygen $\left(p_{\mathrm{O}_{2}}\right)$ and doping). ${ }^{44}$ Next, to get the insights on synergistic effect of codoping, electronic density of states for pristine, monodoped and codoped $\mathrm{SrTiO}_{3}$ have been compared. In addition, the optical response using single-shot $\mathrm{GW}^{45,46}$ method is also analyzed. Finally, from the perspective of its usage in photocatalytic water splitting, we have examined the band edges alignment of (un)doped $\mathrm{SrTiO}_{3}$ w.r.t. water redox potential levels.

\section{Computational Methods}

We have carried out the DFT calculations using the Vienna ab initio simulation package (VASP). ${ }^{47,48}$ The projector-augmented wave (PAW) potentials ${ }^{49}$ are used to describe the ionelectron interactions in all the elemental constituents, viz. Sr, Ti, Mn, O, and N, that contain ten, four, seven, six, and five valence electrons, respectively. The total energy calculations are performed using hybrid exchange-correlation (xc) functional HSE06 ${ }^{50}$ (for validation of xc functionals, see Sec. VI in SI). To introduce defects in $\mathrm{SrTiO}_{3}$, we have used a 40-atom supercell, which is constructed by a $2 \times 2 \times 2$ repetition of cubic $\mathrm{SrTiO}_{3}$ unit cell ( 5 atoms). A k-point mesh of $4 \times 4 \times 4$ is used, which is generated using Monkhorst-Pack ${ }^{51}$ scheme. The self consistency loop is converged with a threshold of $0.01 \mathrm{meV}$ energy. The cutoff energy of 
$600 \mathrm{eV}$ is used for the plane wave basis set. Note that we have performed the spin-polarized calculations because the doped systems contain unpaired electrons. The quasiparticle energy calculations have been carried out using single-shot $\mathrm{G}_{0} \mathrm{~W}_{0}$ approximation starting from the orbitals obtained using HSE06 xc functional. The polarizability calculations are performed on a grid of 50 frequency points. To make computation feasible, the number of bands is set to 384 , which is typically four times the number of occupied orbitals.

\section{Results and discussion}

\section{Stabilitiy of defects in $\mathrm{SrTiO}_{3}: a b$ initio atomistic thermodynamics}

On doping $\mathrm{SrTiO}_{3}$ with a nonmetal dopant (e.g. N), the possible defects that could occur are: $\mathrm{N}_{\mathrm{O}}$ ( $\mathrm{N}$ substituted at $\mathrm{O}$ position), $\mathrm{N}_{\mathrm{i}}$ ( $\mathrm{N}$ as an interstitial making bond with $\left.\mathrm{O}\right)$, and $\left(\mathrm{N}_{2}\right)_{\mathrm{O}}$ split-interstitial (one $\mathrm{N}$ is at interstitial position and another one is substituted the nearby O, making bond with each other). ${ }^{22,38,39,52}$ In the case of metal (e.g Mn) doping, Mn could be substituted either at $\mathrm{Ti}\left(\mathrm{Mn}_{\mathrm{Ti}}\right)$ or $\mathrm{Sr}\left(\mathrm{Mn}_{\mathrm{Sr}}\right)$ site, or it could also be present as an interstitial $\left(\mathrm{Mn}_{\mathrm{i}}\right)$ in $\mathrm{SrTiO}_{3} \cdot{ }^{40,41}$ Note that these defects are not stable in neutral form because of the uncompensated charge. Therefore, we have calculated the stability of charged defects in addition to neutral defects with charge states $q(-2,-1,0,+1,+2) .{ }^{44,52,53}$

To analyze the thermodynamic stability of the defected configuration w.r.t. pristine $\mathrm{SrTiO}_{3}$, we have calculated the formation energy by means of ab initio atomistic thermodynamics. ${ }^{44,53-56}$ For a X-related defect with charge state $q$, the formation energy $\left(\mathrm{E}_{\mathrm{f}}\left(\mathrm{X}^{q}\right)\right)$ is calculated as follow: ${ }^{44,52,53}$

$$
\begin{aligned}
\mathrm{E}_{\mathrm{f}}\left(\mathrm{X}^{q}\right)= & \mathrm{E}_{\mathrm{tot}}\left(\mathrm{X}^{q}\right)-\mathrm{E}_{\mathrm{tot}}\left(\text { pristine }^{0}\right)-\sum_{i} n_{i} \mu_{i} \\
& +q\left(\mu_{\mathrm{e}}+\mathrm{VBM}+\Delta \mathrm{V}\right)
\end{aligned}
$$

where, $\mathrm{E}_{\text {tot }}\left(\mathrm{X}^{q}\right)$ and $\mathrm{E}_{\text {tot }}\left(\right.$ pristine $\left.^{0}\right)$ are the total DFT energies with defect (at charge $q$ ) 
and pristine neutral respectively. $n_{i}$ is the number of atoms $i$ added (positive) or removed (negative) from the system and $\mu_{i}$ is the corresponding chemical potential. $\mu_{i}$ is referenced from the total DFT energy $\left(\mathrm{E}_{\mathrm{tot}}(i)\right)$ of species $i$, i.e., $\mu_{i}=\Delta \mu_{i}+\mathrm{E}_{\mathrm{tot}}(i)$. The chemical potentials, $\Delta \mu_{i}$ s have been chosen carefully to reflect the appropriate environmental growth conditions (see Sec. II in SI). $\mu_{\mathrm{e}}$ is the chemical potential of electron varied from VBM to $\mathrm{CBm}$ of the pristine system and $\Delta \mathrm{V}$ accounts for the core level alignment of the defected system w.r.t. the pristine neutral system.

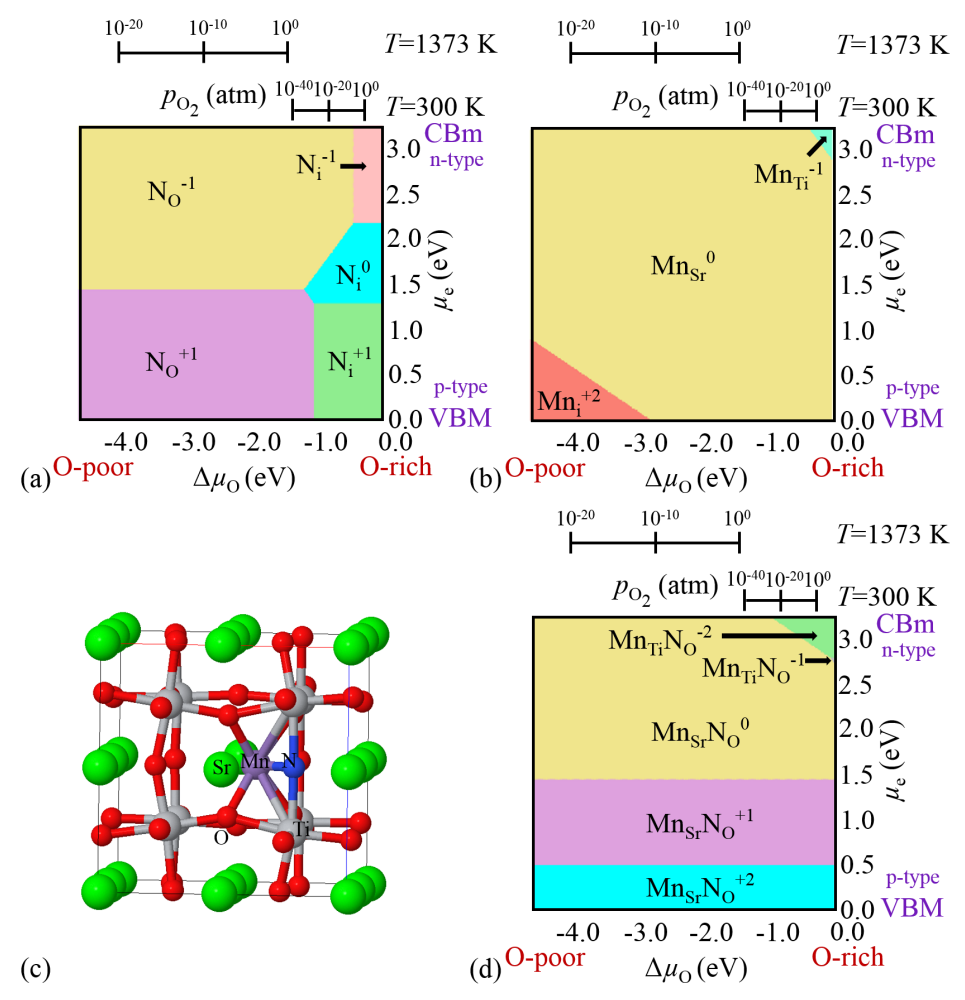

Figure 1: 2D projection of the 3D phase diagram that manifests the stable phases of (a) Nrelated, (b) Mn-related and (d) (N-Mn)-related charged defects having minimum formation energy as a function of $\mu_{\mathrm{e}}$ and $\Delta \mu_{\mathrm{O}}$. Here, on x-axis, $\Delta \mu_{\mathrm{O}}$ is varied according to $T$ and $p_{\mathrm{O}_{2}}$, and on y-axis, $\mu_{\mathrm{e}}$ is varied from VBM to $\mathrm{CBm}$ of pristine $\mathrm{SrTiO}_{3}$. Colored regions show the most stable phases having minimum formation energy at a given environmental condition. Top axes are showing the pressure $\left(p_{\mathrm{O}_{2}}\right)$ range at two temperatures: $T=300 \mathrm{~K}$ and $1373 \mathrm{~K}$. (c) Ball and stick model of optimized structure of $\mathrm{Mn}_{\mathrm{Sr}} \mathrm{N}_{\mathrm{O}}$ defect configuration.

The optimized structures of all the doped and pristine $\mathrm{SrTiO}_{3}$ supercell are shown in Figure $\mathrm{S} 1 . \quad \mathrm{SrTiO}_{3}$ has a cubic structure space group $P m \overline{3} m$ at room temperature. On 
doping $\mathrm{N}$ in pristine, $\mathrm{N}$-related defects, viz. $\mathrm{N}_{\mathrm{O}}, \mathrm{N}_{\mathrm{i}}$, and $\left(\mathrm{N}_{2}\right)_{\mathrm{O}}$ could form. $\mathrm{N}_{\mathrm{O}}$ shows negligible distortion, whereas $\mathrm{N}_{\mathrm{i}}$ and $\left(\mathrm{N}_{2}\right)_{\mathrm{O}}$ show more distortion in the lattice. We can sum up about the stability of all the three configurations of N-related defects at different environmental conditions by observing the 3D phase diagram as shown in Figure 1a. Here, on x-axis, $\Delta \mu_{\mathrm{O}}$ is varied from O-poor to O-rich condition in accordance with $T$ and $p_{\mathrm{O}_{2}}$. On y-axis, we have scanned the entire forbidden region by means of $\mu_{\mathrm{e}}$, which is referenced from VBM of pristine $\mathrm{SrTiO}_{3}$. On z-axis, we have shown the most stable phases having minimum formation energy at a given environmental condition using the colored surfaces. The charge states +1 and -1 are energetically stable in case of $\mathrm{N}_{\mathrm{O}}$ near VBM and CBm, respectively. $\mathrm{N}_{\mathrm{i}}$ is energetically stable in charge states $+1,0$, and -1 . The positive charge states are more favorable for smaller value of $\mu_{\mathrm{e}}$, i.e., near VBM (p-type), whereas negative charge states are stable near CBm (n-type) for larger value of $\mu_{\mathrm{e}}$. Since O-poor and O-rich conditions also correspond to lesser and more content of $\mathrm{O}$, respectively, therefore $\mathrm{N}_{\mathrm{O}}$ is difficult/easier to form in O-rich/O-poor condition. $\mathrm{N}_{\mathrm{O}}$ is stable with charge state -1 near CBm as it has one electron less than the $\mathrm{O}$ atom. The thermodynamic transition level $(+/-)$ lies in between the VBM and CBm indicating that $\mathrm{N}_{\mathrm{O}}$ acts both as a deep donor/acceptor depending on the nature of doping (i.e. p-type or n-type). From Figure 1a, we can easily see that $\mathrm{N}_{\mathrm{O}}$ is the predominant defect in $\mathrm{N}$ doped $\mathrm{SrTiO}_{3}$ for a wide range of environmental conditions including the experimental growth condition $\left(T=1373 \mathrm{~K}, p_{\mathrm{O}_{2}}=1 \mathrm{~atm}^{21}\right)$, whereas $\mathrm{N}_{\mathrm{i}}$ is only favorable in O-rich condition (in accordance with 2D phase diagram (see Figure S2)).

On doping $\mathrm{Mn}$ in $\mathrm{SrTiO}_{3}$, the structures that could form are $\mathrm{Mn}_{\mathrm{Sr}}, \mathrm{Mn}_{\mathrm{Ti}}$, and $\mathrm{Mn}_{\mathrm{i}}$. In case of $\mathrm{Mn}_{\mathrm{Sr}}$, only neutral defect is stable, which signifies that $\mathrm{Mn}$ exists in $\mathrm{Mn}^{2+}$ oxidation state when substituted at $\mathrm{Sr}\left(\mathrm{Sr}^{2+}\right.$ oxidation state) site in $\mathrm{SrTiO}_{3}$ (see Figure $\left.1 \mathrm{~b}\right) . \mathrm{Mn}_{\mathrm{Ti}}$ is stable in -1 charge state indicating that in addition to $\mathrm{Mn}^{4+}$ oxidation state, $\mathrm{Mn}^{3+}$ oxidation state could also exist, though unlikely, when $\mathrm{Mn}$ is substituted at $\mathrm{Ti}$ ( $\mathrm{Ti}^{4+}$ oxidation state) site. $\mathrm{Mn}_{\mathrm{i}}$ with +2 charge state is stable in p-type $\mathrm{SrTiO}_{3}$ under O-poor condition, while $\mathrm{Mn}_{\mathrm{Ti}}$ with -1 charge state is stable in n-type $\mathrm{SrTiO}_{3}$ under O-rich condition as shown in 
the 3D phase diagram (see Figure 1b). Neutral $\mathrm{Mn}_{\mathrm{Sr}}$ is the prominent defect under all the three environmental conditions. The formation energy for $\mathrm{Mn}$ doped $\mathrm{SrTiO}_{3}$ in all oxygen environmental conditions is small, particularly in O-intermediate condition (see Figure S3), which implies that it is easier to dope $\mathrm{Mn}$ in $\mathrm{SrTiO}_{3}$.

From the above analysis, we conclude that in the case of monodoped $\mathrm{SrTiO}_{3}$, substitutional doping is the most stable for a wider region of the environmental conditions including the experimental growth conditions. Therefore, we have considered only the substitutional position for codoping of $\mathrm{Mn}$ and $\mathrm{N}$ in $\mathrm{SrTiO}_{3}$. The formation energy of $\mathrm{Mn}_{\mathrm{Sr}} \mathrm{N}_{\mathrm{O}}$ $\left(\mathrm{E}_{\mathrm{f}}\left(\mathrm{Mn}_{\mathrm{Sr}} \mathrm{N}_{\mathrm{O}}^{q}\right)\right)$ is calculated as follow:

$$
\begin{aligned}
\mathrm{E}_{\mathrm{f}}\left(\mathrm{Mn}_{\mathrm{Sr}} \mathrm{N}_{\mathrm{O}}^{q}\right)= & \mathrm{E}_{\text {tot }}\left(\mathrm{Mn}_{\mathrm{Sr}} \mathrm{N}_{\mathrm{O}}^{q}\right)-\mathrm{E}_{\text {tot }}\left(\mathrm{SrTiO}_{3}^{0}\right)+\mu_{\mathrm{O}}-\mu_{\mathrm{N}} \\
& +\mu_{\mathrm{Sr}}-\mu_{\mathrm{Mn}}+q\left(\mu_{\mathrm{e}}+\mathrm{VBM}+\Delta \mathrm{V}\right),
\end{aligned}
$$

where $\mathrm{E}_{\text {tot }}\left(\mathrm{Mn}_{\mathrm{Sr}} \mathrm{N}_{\mathrm{O}}^{q}\right)$ and $\mathrm{E}_{\text {tot }}\left(\mathrm{SrTiO}_{3}^{0}\right)$ are the DFT energies of the codoped system (Mn at $\mathrm{Sr}$ and $\mathrm{N}$ at $\mathrm{O}$ ) with charge $q$ and the pristine neutral $\mathrm{SrTiO}_{3}$, respectively. $\mu_{\mathrm{O}}$ and $\mu_{\mathrm{N}}$ are the chemical potential of oxygen and nitrogen atom, referenced from the total DFT energy with addition of zero point energy of $\mathrm{O}_{2}$ and $\mathrm{N}_{2}$ molecules, respectively, i.e., $\mu_{\mathrm{O}}=$ $\Delta \mu_{\mathrm{O}}+\frac{1}{2}\left(\mathrm{E}_{\mathrm{tot}}\left(\mathrm{O}_{2}\right)+\frac{\mathrm{h} \nu_{\mathrm{OO}}}{2}\right)$ and $\mu_{\mathrm{N}}=\Delta \mu_{\mathrm{N}}+\frac{1}{2}\left(\mathrm{E}_{\mathrm{tot}}\left(\mathrm{N}_{2}\right)+\frac{\mathrm{h} \nu_{\mathrm{NN}}}{2}\right)$. In the latter terms, $\nu_{\mathrm{OO}}$ and $\nu_{\mathrm{NN}}$ are the $\mathrm{O}-\mathrm{O}$ and $\mathrm{N}-\mathrm{N}$ stretching frequencies, respectively. The chemical potential $\mu_{\mathrm{X}}=\Delta \mu_{\mathrm{X}}+\mathrm{E}_{\text {tot }}(\mathrm{X})$ (where, $\mathrm{X}=\mathrm{Mn}, \mathrm{Sr}$ and Ti). The chemical potential $\Delta \mu_{\mathrm{X}}(\mathrm{X}=\mathrm{O}$, N, Mn, Sr, and Ti) are chosen carefully (see Sec. II in SI). Figure 1d shows the 3D phase diagram for the stability of codoped systems. $\mathrm{Mn}_{\mathrm{Sr}} \mathrm{N}_{\mathrm{O}}$ is the predominant defect in all the environmental growth conditions and is stable in $+2,+1$, and neutral charge states. This will act as a donor in p-type $\mathrm{SrTiO}_{3}$. Whereas, $\mathrm{Mn}_{\mathrm{Ti}} \mathrm{N}_{\mathrm{O}}$ is stable only for a smaller region in extreme O-rich/Ti-poor condition with charge states -1 and -2 near CBm (n-type), i.e. it will act as an acceptor (see Figure 1d). To further confirm that the formation of defect pair $(\mathrm{N}-\mathrm{Mn})$ in $\mathrm{SrTiO}_{3}$ is stable, the binding energy $\left(\mathrm{E}_{\mathrm{b}}\right)$ of the defect pairs $(\mathrm{N}-\mathrm{Mn})$ in $\mathrm{SrTiO}_{3}$ has also been checked. ${ }^{32,57} \mathrm{~A}$ more negative value of $\mathrm{E}_{\mathrm{b}}$ indicates that defect pair is more 
stable when both the dopants are present in the sample. $\mathrm{E}_{\mathrm{b}}$ for $\mathrm{Mn}_{\mathrm{Sr}} \mathrm{N}_{\mathrm{O}}$ and $\mathrm{Mn}_{\mathrm{Ti}} \mathrm{N}_{\mathrm{O}}$ pairs are -1.46 and $-0.33 \mathrm{eV}$, respectively. These values indicate that defect pairs are more stable than the isolated impurities in $\mathrm{SrTiO}_{3}$ supercell. Also, $\mathrm{Mn}_{\mathrm{Sr}} \mathrm{N}_{\mathrm{O}}$ is more stable configuration than $\mathrm{Mn}_{\mathrm{Ti}} \mathrm{N}_{\mathrm{O}}$ since $\mathrm{Mn}_{\mathrm{Sr}} \mathrm{N}_{\mathrm{O}}$ has higher (more negative) binding energy than $\mathrm{Mn}_{\mathrm{Ti}} \mathrm{N}_{\mathrm{O}}$. In the codoped system, Mn acts as a donor, whereas $\mathrm{N}$ acts as an acceptor. The charge transfer takes place from donor to acceptor and strong Coulomb interaction arises between positively charged donor and negatively charged acceptor. Hence, the defect pair is stable. The extra stability in $\mathrm{Mn}_{\mathrm{Sr}} \mathrm{N}_{\mathrm{O}}$ is due to the shift of Mn away from the $\mathrm{Sr}$ center towards $\mathrm{N}$ as shown in Figure 1c and making strong bonds with its neighbor atoms.

\section{Electronic structure analysis}

To get more insights about the effect of dopants in $\mathrm{SrTiO}_{3}$, we have calculated atom projected density of states (pDOS). The DOS plots for pristine and monodoped $\mathrm{SrTiO}_{3}$ are shown in Figure 2(a-d). In pristine, the O 2p orbitals contribute to VBM, and Ti 3d orbitals contribute to $\mathrm{CBm}$ with a wide band gap of $3.28 \mathrm{eV}$. The DOS of pristine is symmetric w.r.t. spin alignments (i.e. spin up or down), whereas in case of $\mathrm{N}_{\mathrm{O}}$, the DOS is asymmetrical due to devoid of an electron in comparison to pristine $\mathrm{SrTiO}_{3}$ (see Figure 2a and 2b). In the latter case, some occupied states are appeared above pristine-VBM and some unoccupied discrete states can also be seen deep inside the forbidden region (since the $\mathrm{N} 2 \mathrm{p}$ orbitals have higher energy than the $\mathrm{O} 2 \mathrm{p}$ orbitals) (see Figure $2 \mathrm{~b}$ ). This leads to reduction in the band gap. However, these midgap states increase the recombination rate and decrease the charge mobility that lead to degradation in the photocatalytic activity.

We have considered two sites for the substitution of Mn, viz. Sr and Ti sites. In case of monodoping of Mn at Sr site, the band gap (3.25 eV) is not getting reduced and thus, cannot induce visible light absorption (see Figure 2c). The occupied and unoccupied states of Mn orbitals are appeared deep inside the valence and conduction band, respectively, indicating that $\mathrm{Mn}_{\mathrm{Sr}}$ is very stable. However, in case of Ti site substitution, we get interesting feature 

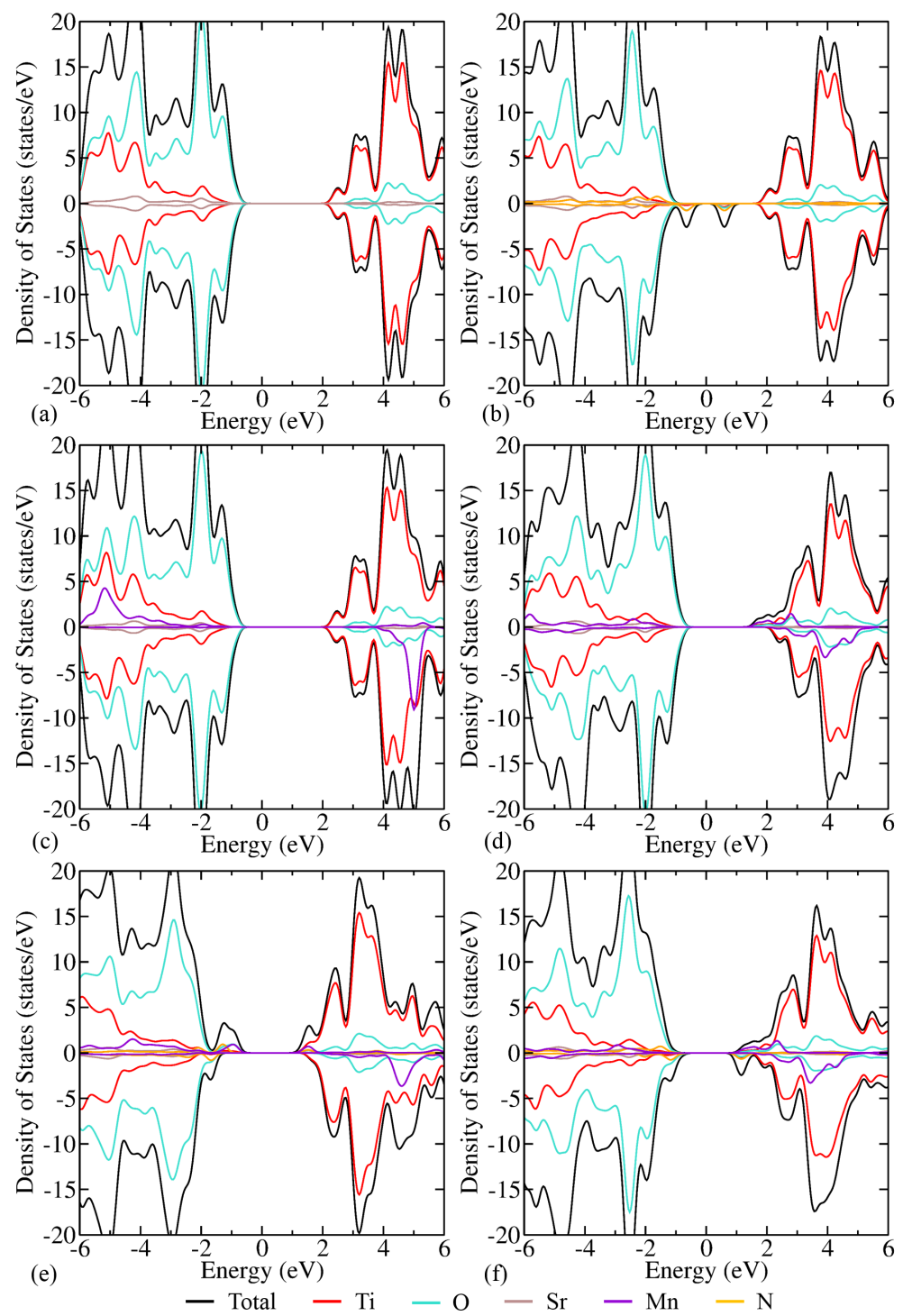

Figure 2: Electronic density of states for the supercell of (a) pristine $\mathrm{SrTiO}_{3}$, (b) $\mathrm{N}_{\mathrm{O}}$, (c) $\mathrm{Mn}_{\mathrm{Sr}}$, (d) $\mathrm{Mn}_{\mathrm{Ti}}$, (e) $\mathrm{Mn}_{\mathrm{Sr}} \mathrm{N}_{\mathrm{O}}$ and (f) $\mathrm{Mn}_{\mathrm{Ti}} \mathrm{N}_{\mathrm{O}}$ type defect. 
in the DOS (see Figure 2d). The localized states bring down the CBm. Hence, the band gap is reduced to $2.57 \mathrm{eV}$, resulting in the visible light absorption. However, due to shift of $\mathrm{CBm}$ in downward direction, its reduction power is degraded. Therefore, it can not be a potential candidate for $\mathrm{H}_{2}$ production from water splitting.

In case of codoping, the substitution of Mn at both sites, $\mathrm{Sr}$ and $\mathrm{Ti}$ in addition to $\mathrm{N}_{\mathrm{O}}$, helps in passivating the localized mid gap states (introduced by $\mathrm{N}$ substitution) and form continuum states as shown in Figure $2 \mathrm{e}$ and $2 \mathrm{f}$. The passivation of states is concomitant with the hybridization of $\mathrm{O}$ and $\mathrm{N}$ orbitals, and $\mathrm{Mn}$ and $\mathrm{O}$ orbitals in $\mathrm{Mn}_{\mathrm{Sr}} \mathrm{N}_{\mathrm{O}}$ defect configuration as shown in Figure 2e (near VBM). However, in the case of $\mathrm{Mn}_{\mathrm{Ti}} \mathrm{N}_{\mathrm{O}}$, Mn states arise only near $\mathrm{CBm}$ as shown in Figure 2f. The recombination of photogenerated charge carriers is suppressed, and the diffusion and mobility are increased owing to the passivation of discrete localized states. The band gaps of $\mathrm{Mn}_{\mathrm{Sr}} \mathrm{N}_{\mathrm{O}}$ and $\mathrm{Mn}_{\mathrm{Ti}} \mathrm{N}_{\mathrm{O}}$ are 2.34 and $1.94 \mathrm{eV}$, respectively, which are the desirable one for visible light absorption. In case of $\mathrm{Mn}_{\mathrm{Ti}} \mathrm{N}_{\mathrm{O}}, \mathrm{CBm}$ is shifted downward by a large amount and hence, adversely affect the reduction power for hydrogen generation. However, in case of $\mathrm{Mn}_{\mathrm{Sr}} \mathrm{N}_{\mathrm{O}}$, this downward shift is very small. Consequently, the codoping of Mn at Sr site and $\mathrm{N}$ at $\mathrm{O}$ site is favorable for overall photocatalytic water splitting. Also, from Figure 1c, we can see a relatively large distortion in case of $\mathrm{Mn}_{\mathrm{Sr}} \mathrm{N}_{\mathrm{O}}$ codoping, which builds up the internal field, that is helpful for photogenerated charge carriers separation and thus, enhances the photocatalytic efficiency. Therefore, $\mathrm{Mn}_{\mathrm{Sr}} \mathrm{N}_{\mathrm{O}}$ codoping in $\mathrm{SrTiO}_{3}$ is the promising candidate to enhance the photocatalytic efficiency and generate hydrogen from water splitting.

\section{Optical properties}

To determine the optical spectra, we have computed the frequency dependent complex dielectric function $\epsilon(\omega)=\epsilon_{1}(\omega)+i \epsilon_{2}(\omega)$ using the $\mathrm{G}_{0} \mathrm{~W}_{0} @$ HSE06 approach (the results with HSE06 are shown in Figure S5 and S6). The real $\left(\epsilon_{1}\right)$ and imaginary $\left(\epsilon_{2}\right)$ part of dielectric function have shown in Figure $3 \mathrm{a}$ and $3 \mathrm{~b}$, respectively. The static $(\omega=0)$ real part 


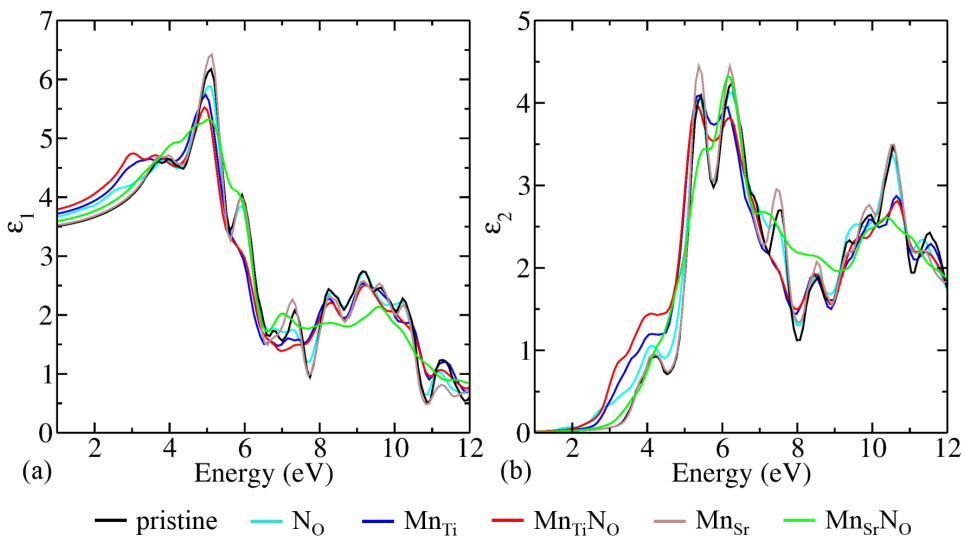

Figure 3: Spatially average (a) real $\left(\epsilon_{1}\right)$ and (b) imaginary $\left(\epsilon_{2}\right)$ part of the dielectric function obtained by $\mathrm{G}_{0} \mathrm{~W}_{0} @ \mathrm{HSE} 06$ for the pristine, monodoped and codoped $\mathrm{SrTiO}_{3}$.

of $\epsilon(\omega)$ for pristine $\mathrm{SrTiO}_{3}$ is found to be 3.46, which is well in agreement with previous findings. ${ }^{58}$ On doping, its value is increased (see Figure 3a). The imaginary part of dielectric function represents the optical absorption (see Figure 3b). We have found the first peak at $4.20 \mathrm{eV}$ for pristine $\mathrm{SrTiO}_{3}$ [experimental value is $4.7 \mathrm{eV}^{59}$ ]. Note that the peaks are shifted towards lower energy region, except for $\mathrm{Mn}_{\mathrm{Sr}}$. Even if the exact numbers may differ from the experimental values, atleast from the trends it's clear that the band gap is getting reduced on doping in $\mathrm{SrTiO}_{3}$. Also, we could note that the onset of the absorption edge is shifting towards the lower region. Hence, the optical response is shifted towards the visible region. The spectra of $\mathrm{Mn}_{\mathrm{Sr}}$ coincides with the pristine supercell of $\mathrm{SrTiO}_{3}$ because there is no reduction in band gap, while in rest of the cases, band gap is reduced (see Figure 3b).

\section{Band edge alignment}

Note that only reduction in band gap can not assure the hydrogen generation via photocatalytic water splitting. The band edges (VBM and CBm) should have appropriate position. For water splitting, the CBm must lie above the water reduction potential level $\left(\mathrm{H}^{+} / \mathrm{H}_{2}\right)$ and VBM must be positioned below water oxidation potential level $\left(\mathrm{O}_{2} / \mathrm{H}_{2} \mathrm{O}\right)$. Firstly, we have aligned the band edges of undoped $\mathrm{SrTiO}_{3}$ w.r.t. water redox potential levels. The $\mathrm{CBm}$ lies $0.8 \mathrm{eV}$ above the water reduction potential $\left(\mathrm{H}^{+} / \mathrm{H}_{2}\right)$ and VBM lies $1.25 \mathrm{eV}$ below water 
oxidation potential. ${ }^{60}$ We see that the position of $\mathrm{CBm}$ and $\mathrm{VBM}$ of the pristine $\mathrm{SrTiO}_{3}$ is consistent with previous findings. ${ }^{37}$ Thereafter, we align the band edges of doped $\mathrm{SrTiO}_{3}$ by observing the shift in energy of the VBM and $\mathrm{CBm}$ w.r.t. undoped $\mathrm{SrTiO}_{3}$. From Figure 4, we have found that in the case of $\mathrm{N}_{\mathrm{O}}$, the VBM is shifted upwards and the CBm is not disturbed. However, some localized states are present deep in the forbidden region, which

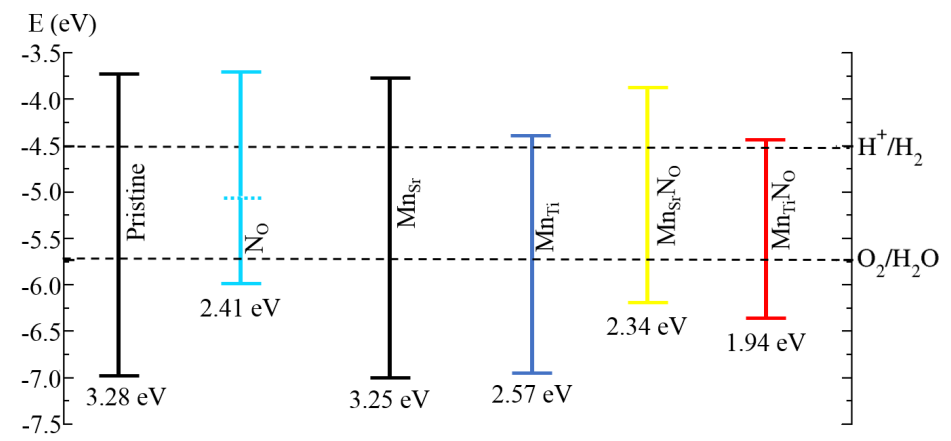

Figure 4: Band edge alignment of (un)doped $\mathrm{SrTiO}_{3}$ w.r.t. water redox potential levels $\left(\mathrm{H}^{+} / \mathrm{H}_{2}, \mathrm{O}_{2} / \mathrm{H}_{2} \mathrm{O}\right)$.

degrade the photocatalytic efficiency. Hence, $\mathrm{N}_{\mathrm{O}}$ is not the promising one for water splitting. In case of $\mathrm{Mn}_{\mathrm{Ti}}$ and $\mathrm{Mn}_{\mathrm{Ti}} \mathrm{N}_{\mathrm{O}}$, the $\mathrm{CBm}$ is shifted downward by a large amount and hence, their reduction power is very low and could not be utilized for hydrogen generation from water. On substituting $\mathrm{Mn}$ at $\mathrm{Sr}$ site, the band gap is not getting reduced and thus, not inducing the visible light response. In the case of $\mathrm{Mn}_{\mathrm{Sr}} \mathrm{N}_{\mathrm{O}}, \mathrm{CBm}$ is shifted by small amount and thus, retaining intact the reduction power. It has a desirable band gap of $2.34 \mathrm{eV}$ and also, does not contain any localized midgap states. In view of this, from the applicability in photocatalytic water splitting, only $\mathrm{Mn}_{\mathrm{Sr}} \mathrm{N}_{\mathrm{O}}$ is the most desirable one. Hence, these theoretical studies help in further future investigations to engineer a device that will be environment friendly.

\section{Effective mass for pristine and $\mathrm{Mn}_{\mathrm{Sr}} \mathrm{N}_{\mathrm{O}}$ codoped $\mathrm{SrTiO}_{3}$}

We have also determined the effective mass of electrons and holes for the pristine and $\mathrm{Mn}_{\mathrm{Sr}} \mathrm{N}_{\mathrm{O}}$ codoped $\mathrm{SrTiO}_{3}$ configurations using HSE06 functional (see Table 1). These have been 
obtained from the curvature of band edges by calculating inverse of second derivative of band energies with respect to $\mathrm{k}$ at band edges. These values of effective masses for pristine system (except for heavy-hole) are validated with previous studies. ${ }^{61-63}$

Table 1: Effective masses (in terms of free-electron mass $m_{e}$ ) at the band edge for pristine and $\mathrm{Mn}_{\mathrm{Sr}} \mathrm{N}_{\mathrm{O}}$ codoped $\mathrm{SrTiO}_{3}$. The masses $\mathbf{m}_{\mathrm{he}}, \mathbf{m}_{\mathrm{le}}, \mathbf{m}_{\mathrm{hh}}$, and $\mathbf{m}_{\mathrm{lh}}$ correspond to heavy-electron, light-electron, heavy-hole, and light-hole band, respectively.

\begin{tabular}{lcccc}
\hline Configuration & $\mathrm{m}_{\mathrm{he}}$ & $\mathrm{m}_{\mathrm{le}}$ & $\mathrm{m}_{\mathrm{hh}}$ & $\mathrm{m}_{\mathrm{lh}}$ \\
\hline pristine & 5.18 & 0.38 & -10.36 & -0.74 \\
$\mathrm{Mn}_{\mathrm{Sr}} \mathrm{N}_{\mathrm{O}}$ & 5.09 & & -2.58 & \\
\hline
\end{tabular}

From Figure 5a, we can see that the pristine has three-fold degeneracy at $\mathrm{CBm}$ (at $\Gamma$ $\mathrm{k}$-point). This degeneracy is lifted as one moves away from $\Gamma \mathrm{k}$-point in the direction of $\mathrm{X}, \mathrm{M}$, or, R k-point. The effective mass of electron/hole due to heavy-, light-electron/hole and spin split-off band is obtained along high symmetry $\Gamma$-X path for pristine. The effective mass of electron/hole corresponding to spin split-off band is found to be same as that for light-electron/hole band. After the validation for pristine system, we have calculated the
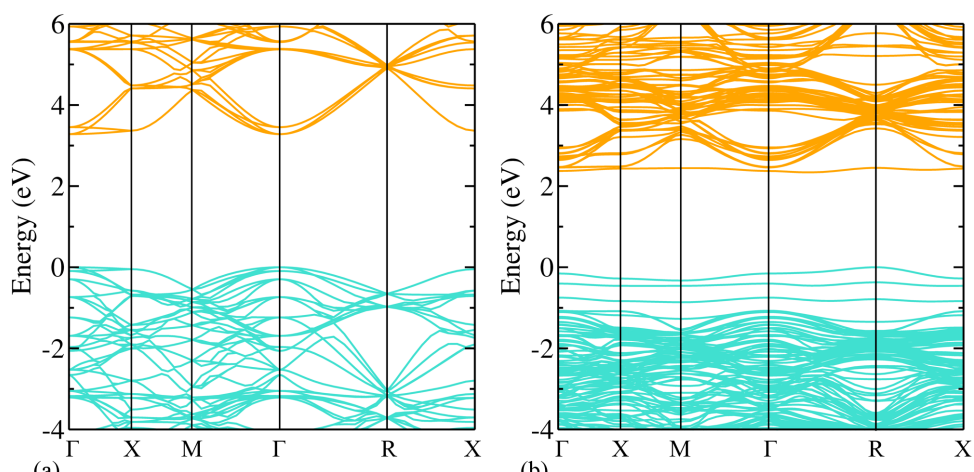

Figure 5: Band structure calculated using hybrid (HSE06) functional of (a) pristine $\mathrm{SrTiO}_{3}$ and (b) $\mathrm{Mn}_{\mathrm{Sr}} \mathrm{N}_{\mathrm{O}}$ codoped $\mathrm{SrTiO}_{3}$.

effective mass for $\mathrm{Mn}_{\mathrm{Sr}} \mathrm{N}_{\mathrm{O}}$. From Figure 5b, we can see that there is no degeneracy of band at CBm and VBM. The defect states constitute the CBm and VBM, which are contributed by the codoping of $\mathrm{Mn}$ at $\mathrm{Sr}$-site and $\mathrm{N}$ at O-site. The flat bands (smaller curvature) indicate

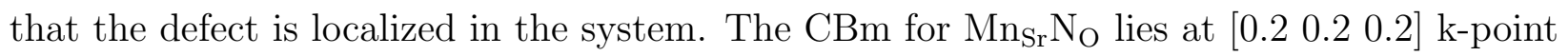


and VBM lies at $\mathrm{R}$ k-point. The effective mass of electron is $5.09 \mathrm{~m}_{\mathrm{e}}$ and $3.04 \mathrm{~m}_{\mathrm{e}}$ along $[0.2$ $0.20 .2]-\Gamma$ and [ 0.20 .20 .2$]$-X directions, respectively. This implies the anisotropy in effective mass. The effective mass of hole is $-2.58 \mathrm{~m}_{\mathrm{e}}$ and $-1.53 \mathrm{~m}_{\mathrm{e}}$ along $\mathrm{R}-\mathrm{\Gamma}$ and $\mathrm{R}-\mathrm{X}$ directions, respectively. The comparable values of effective mass of electron for codoped and pristine systems indicate that the mobility will not be affected much due to the shallower defect level. These effective mass studies further assist future experimental and theoretical investigations to tailor the transport properties of the system.

\section{Conclusions}

In summary, we have systematically studied the thermodynamic stability of different types of dopants and codopants in $\mathrm{SrTiO}_{3}$ using hybrid DFT and ab initio thermodynamics. Our results indicate that $\mathrm{Mn}_{\mathrm{Sr}} \mathrm{N}_{\mathrm{O}}$ is the stable defect configuration under equilibrium growth conditions. We have found that despite monodopant-related defects help in reducing the band gap, they generate localized states deep inside the band gap. These states act as recombination centers, which in turn reduce the photocatalytic efficiency. Thus, monodoping of both $\mathrm{N}$ or $\mathrm{Mn}$ can induce visible light absorption, but none of them are suitable for photocatalytic activity. The codoping reduces the band gap to ideal visible region as well as passivates the localized states to form the continuous band with suitable band edge positions. We have observed that the calculated effective mass of electron for codoped system is found to be similar to that of pristine system. This indicates that electron mobility is not reduced much due to the shallower defect level. We find that $\mathrm{Mn}_{\mathrm{Sr}} \mathrm{N}_{\mathrm{O}}$ codoped $\mathrm{SrTiO}_{3}$ could be a potential candidate for producing hydrogen via photocatalytic water splitting.

\section{Acknowledgement}

MK acknowledges CSIR, India, for the junior research fellowship [grant no. 09/086(1292)/2017EMR-I]. PB acknowledges UGC, India, for the senior research fellowship [grant no. 20/12/2015 
(ii) EUV]. SS acknowledges CSIR, India, for the senior research fellowship [grant no. 09/086 (1231)/2015-EMR-I]. SB acknowledges the financial support from YSS-SERB research grant, DST, India (grant no. YSS/2015/001209). We acknowledge the High Performance Computing (HPC) facility at IIT Delhi for computational resources.

\section{Supporting Information Available}

The following files are available free of charge. Details of choice of the codopants and chemical potentials, validation of exchange-correlation functional, and optical response using hybrid functional could be found in the supporting information file.

\section{References}

(1) Chen, X.; Shen, S.; Guo, L.; Mao, S. S. Semiconductor-based photocatalytic hydrogen generation. Chemical Reviews 2010, 110, 6503-6570.

(2) Chen, C.; Ma, W.; Zhao, J. Semiconductor-mediated photodegradation of pollutants under visible-light irradiation. Chem. Soc. Rev. 2010, 39, 4206-4219.

(3) Kudo, A.; Miseki, Y. Heterogeneous photocatalyst materials for water splitting. Chem. Soc. Rev. 2009, 38, 253-278.

(4) Kubacka, A.; Fernández-García, M.; Colón, G. Advanced nanoarchitectures for solar photocatalytic applications. Chemical Reviews 2012, 112, 1555-1614.

(5) Manikandan, M.; Tanabe, T.; Li, P.; Ueda, S.; Ramesh, G. V.; Kodiyath, R.; Wang, J.; Hara, T.; Dakshanamoorthy, A.; Ishihara, S. et al. Photocatalytic water splitting under visible light by mixed-valence $\mathrm{Sn}_{3} \mathrm{O}_{4}$. ACS Applied Materials \& Interfaces 2014, 6, 3790-3793. 
(6) Zhao, P.; Liang, Y.; Ma, Y.; Huang, B.; Dai, Y. Janus chromium dichalcogenide monolayers with low carrier recombination for photocatalytic overall water-splitting under infrared light. The Journal of Physical Chemistry C 2019, 123, 4186-4192.

(7) Domen, K.; Kudo, A.; Onishi, T.; Kosugi, N.; Kuroda, H. Photocatalytic decomposition of water into hydrogen and oxygen over nickel(II) oxide-strontium titanate $\left(\mathrm{SrTiO}_{3}\right)$ powder. 1. Structure of the catalysts. The Journal of Physical Chemistry 1986, 90, $292-295$.

(8) Ahuja, S.; Kutty, T. Nanoparticles of $\mathrm{SrTiO}_{3}$ prepared by gel to crystallite conversion and their photocatalytic activity in the mineralization of phenol. Journal of Photochemistry and Photobiology A: Chemistry 1996, 97, 99-107.

(9) Iwashina, K.; Kudo, A. Rh-doped $\mathrm{SrTiO}_{3}$ photocatalyst electrode showing cathodic photocurrent for water splitting under visible-light irradiation. Journal of the American Chemical Society 2011, 133, 13272-13275.

(10) Zhang, Q.; Huang, Y.; Xu, L.; Cao, J.-j.; Ho, W.; Lee, S. C. Visible-light-active plasmonic $\mathrm{Ag}-\mathrm{SrTiO}_{3}$ nanocomposites for the degradation of NO in air with high selectivity. ACS Applied Materials 8 Interfaces 2016, 8, 4165-4174.

(11) Niishiro, R.; Tanaka, S.; Kudo, A. Hydrothermal-synthesized $\mathrm{SrTiO}_{3}$ photocatalyst codoped with rhodium and antimony with visible-light response for sacrificial $\mathrm{H}_{2}$ and $\mathrm{O}_{2}$ evolution and application to overall water splitting. Applied Catalysis B: Environmental 2014, 150-151, 187-196.

(12) Tan, H.; Zhao, Z.; Zhu, W.-b.; Coker, E. N.; Li, B.; Zheng, M.; Yu, W.; Fan, H.; Sun, Z. Oxygen vacancy enhanced photocatalytic activity of pervoskite $\mathrm{SrTiO}_{3}$. ACS Applied Materials $\mathscr{E}$ Interfaces 2014, 6, 19184-19190.

(13) Zhang, K. H. L.; Wu, R.; Tang, F.; Li, W.; Oropeza, F. E.; Qiao, L.; Lazarov, V. K.; Du, Y.; Payne, D. J.; MacManus-Driscoll, J. L. et al. Electronic structure and band 
alignment at the $\mathrm{NiO}$ and $\mathrm{SrTiO}_{3}$ p-n heterojunctions. ACS Applied Materials $\&$ Interfaces 2017, 9, 26549-26555.

(14) Konta, R.; Ishii, T.; Kato, H.; Kudo, A. Photocatalytic activities of noble metal ion doped $\mathrm{SrTiO}_{3}$ under visible light irradiation. The Journal of Physical Chemistry B 2004, 108, 8992-8995.

(15) Chen, H.-C.; Huang, C.-W.; Wu, J. C. S.; Lin, S.-T. Theoretical investigation of the metal-doped $\mathrm{SrTiO}_{3}$ photocatalysts for water splitting. The Journal of Physical Chemistry C 2012, 116, 7897-7903.

(16) Niishiro, R.; Kato, H.; Kudo, A. Nickel and either tantalum or niobium-codoped $\mathrm{TiO}_{2}$ and $\mathrm{SrTiO}_{3}$ photocatalysts with visible-light response for $\mathrm{H}_{2}$ or $\mathrm{O}_{2}$ evolution from aqueous solutions. Phys. Chem. Chem. Phys. 2005, 7, 2241-2245.

(17) Yu, H.; Ouyang, S.; Yan, S.; Li, Z.; Yu, T.; Zou, Z. Solgel hydrothermal synthesis of visible-light-driven Cr-doped $\mathrm{SrTiO}_{3}$ for efficient hydrogen production. J. Mater. Chem. 2011, 21, 11347-11351.

(18) Kawasaki, S.; Nakatsuji, K.; Yoshinobu, J.; Komori, F.; Takahashi, R.; Lippmaa, M.; Mase, K.; Kudo, A. Epitaxial Rh-doped $\mathrm{SrTiO}_{3}$ thin film photocathode for water splitting under visible light irradiation. Applied Physics Letters 2012, 101, 033910.

(19) Liu, P.; Nisar, J.; Pathak, B.; Ahuja, R. Hybrid density functional study on $\mathrm{SrTiO}_{3}$ for visible light photocatalysis. International Journal of Hydrogen Energy 2012, 37, 11611-11617.

(20) Guo, Y.; Qiu, X.; Dong, H.; Zhou, X. Trends in non-metal doping of the $\mathrm{SrTiO}_{3}$ surface: A hybrid density functional study. Phys. Chem. Chem. Phys. 2015, 17, 21611-21621.

(21) Wang, J.; Yin, S.; Komatsu, M.; Zhang, Q.; Saito, F.; Sato, T. Preparation and char- 
acterization of nitrogen doped $\mathrm{SrTiO}_{3}$ photocatalyst. Journal of Photochemistry and Photobiology A: Chemistry 2004, 165, 149-156.

(22) Mi, Y. Y.; Wang, S. J.; Chai, J. W.; Pan, J. S.; Huan, C. H. A.; Feng, Y. P.; Ong, C. K. Effect of nitrogen doping on optical properties and electronic structures of $\mathrm{SrTiO}_{3}$ films. Applied Physics Letters 2006, 89, 231922.

(23) Zhang, C.; Jia, Y.; Jing, Y.; Yao, Y.; Ma, J.; Sun, J. Effect of non-metal elements (B, C, N, F, P, S) mono-doping as anions on electronic structure of $\mathrm{SrTiO}_{3}$. Computational Materials Science 2013, 79, 69-74.

(24) Zou, F.; Jiang, Z.; Qin, X.; Zhao, Y.; Jiang, L.; Zhi, J.; Xiao, T.; Edwards, P. P. Template-free synthesis of mesoporous N-doped $\mathrm{SrTiO}_{3}$ perovskite with high visiblelight-driven photocatalytic activity. Chem. Commun. 2012, 48, 8514-8516.

(25) Reunchan, P.; Ouyang, S.; Umezawa, N.; Xu, H.; Zhang, Y.; Ye, J. Theoretical design of highly active $\mathrm{SrTiO}_{3}$-based photocatalysts by a codoping scheme towards solar energy utilization for hydrogen production. J. Mater. Chem. A 2013, 1, 4221-4227.

(26) Ouyang, S.; Tong, H.; Umezawa, N.; Cao, J.; Li, P.; Bi, Y.; Zhang, Y.; Ye, J. Surfacealkalinization-induced enhancement of photocatalytic $\mathrm{H}_{2}$ evolution over $\mathrm{SrTiO}_{3}$-based photocatalysts. Journal of the American Chemical Society 2012, 134, 1974-1977.

(27) Comes, R. B.; Sushko, P. V.; Heald, S. M.; Colby, R. J.; Bowden, M. E.; Chambers, S. A. Band-gap reduction and dopant interaction in epitaxial La,Cr co-doped $\mathrm{SrTiO}_{3}$ thin films. Chemistry of Materials 2014, 26, 7073-7082.

(28) Miyauchi, M.; Takashio, M.; Tobimatsu, H. Photocatalytic activity of $\mathrm{SrTiO}_{3}$ codoped with nitrogen and lanthanum under visible light illumination. Langmuir 2004, 20, 232-236. 
(29) Chen, W.; Liu, H.; Li, X.; Liu, S.; Gao, L.; Mao, L.; Fan, Z.; Shangguan, W.; Fang, W.; Liu, Y. Polymerizable complex synthesis of $\mathrm{SrTiO}_{3}$ : (Cr/Ta) photocatalysts to improve photocatalytic water splitting activity under visible light. Applied Catalysis B: Environmental 2016, 192, 145-151.

(30) Wei, W.; Dai, Y.; Guo, M.; Yu, L.; Huang, B. Density functional characterization of the electronic structure and optical properties of N-Doped, La-Doped, and N/La-codoped $\mathrm{SrTiO}_{3}$. The Journal of Physical Chemistry C 2009, 113, 15046-15050.

(31) Wei, W.; Dai, Y.; Guo, M.; Yu, L.; Jin, H.; Han, S.; Huang, B. Codoping synergistic effects in N-doped $\mathrm{SrTiO}_{3}$ for higher energy conversion efficiency. Phys. Chem. Chem. Phys. 2010, 12, 7612-7619.

(32) Gai, Y.; Li, J.; Li, S.-S.; Xia, J.-B.; Wei, S.-H. Design of narrow-gap $\mathrm{TiO}_{2}$ : A passivated codoping approach for enhanced photoelectrochemical activity. Phys. Rev. Lett. 2009, 102, 036402.

(33) Modak, B.; Ghosh, S. K. Role of F in improving the photocatalytic activity of Rh-doped $\mathrm{SrTiO}_{3}$. The Journal of Physical Chemistry C 2015, 119, 7215-7224.

(34) Modak, B.; Ghosh, S. K. Enhancement of visible light photocatalytic activity of $\mathrm{SrTiO}_{3}$ : A hybrid density functional study. The Journal of Physical Chemistry C 2015, 119, 23503-23514.

(35) Bahers, T. L.; Takanabe, K. Combined theoretical and experimental characterizations of semiconductors for photoelectrocatalytic applications. Journal of Photochemistry and Photobiology C: Photochemistry Reviews 2019, 40, 212-233.

(36) Walter, M. G.; Warren, E. L.; McKone, J. R.; Boettcher, S. W.; Mi, Q.; Santori, E. A.; Lewis, N. S. Solar water splitting cells. Chemical Reviews 2010, 110, 6446-6473. 
(37) Stevanović, V.; Lany, S.; Ginley, D. S.; Tumas, W.; Zunger, A. Assessing capability of semiconductors to split water using ionization potentials and electron affinities only. Phys. Chem. Chem. Phys. 2014, 16, 3706-3714.

(38) Sun, T.; Lu, M. Modification of $\mathrm{SrTiO}_{3}$ surface by nitrogen ion bombardment for enhanced photocatalysis. Applied Surface Science 2013, 274, 176-180.

(39) Liu, C. M.; Zu, X. T.; Zhou, W. L. Photoluminescence of nitrogen doped $\mathrm{SrTiO}_{3}$. Journal of Physics D: Applied Physics 2007, 40, 7318-7322.

(40) Tkach, A.; Vilarinho, P. M.; Kholkin, A. L. Structure-microstructure-dielectric tunability relationship in Mn-doped strontium titanate ceramics. Acta Materialia 2005, 53, 5061-5069.

(41) Yang, H.; Kotula, P. G.; Sato, Y.; Chi, M.; Ikuhara, Y.; Browning, N. D. Segregation of $\mathrm{Mn}^{2+}$ dopants as interstitials in $\mathrm{SrTiO}_{3}$ grain boundaries. Materials Research Letters 2014, 2, 16-22.

(42) Hohenberg, P.; Kohn, W. Inhomogeneous electron gas. Phys. Rev. 1964, 136, B864B871.

(43) Kohn, W.; Sham, L. J. Self-consistent equations including exchange and correlation effects. Phys. Rev. 1965, 140, A1133-A1138.

(44) Bhattacharya, S.; Berger, D.; Reuter, K.; Ghiringhelli, L. M.; Levchenko, S. V. Theoretical evidence for unexpected O-rich phases at corners of MgO surfaces. Phys. Rev. Materials 2017, 1, 071601.

(45) Hedin, L. New method for calculating the one-particle Green's function with application to the electron-gas problem. Phys. Rev. 1965, 139, A796-A823.

(46) Hybertsen, M. S.; Louie, S. G. First-principles theory of quasiparticles: Calculation of band gaps in semiconductors and insulators. Phys. Rev. Lett. 1985, 55, 1418-1421. 
(47) Kresse, G.; Furthmüller, J. Efficiency of ab-initio total energy calculations for metals and semiconductors using a plane-wave basis set. Computational Materials Science 1996, 6, 15-50.

(48) Kresse, G.; Joubert, D. From ultrasoft pseudopotentials to the projector augmentedwave method. Phys. Rev. B 1999, 59, 1758-1775.

(49) Blöchl, P. E. Projector augmented-wave method. Phys. Rev. B 1994, 50, 17953-17979.

(50) Krukau, A. V.; Vydrov, O. A.; Izmaylov, A. F.; Scuseria, G. E. Influence of the exchange screening parameter on the performance of screened hybrid functionals. The Journal of Chemical Physics 2006, 125, 224106.

(51) Monkhorst, H. J.; Pack, J. D. Special points for Brillouin-zone integrations. Phys. Rev. B 1976, 13, 5188-5192.

(52) Basera, P.; Saini, S.; Arora, E.; Singh, A.; Kumar, M.; Bhattacharya, S. Stability of non-metal dopants to tune the photo-absorption of $\mathrm{TiO}_{2}$ at realistic temperatures and oxygen partial pressures: A hybrid DFT study. Scientific reports 2019, 9, 1-13.

(53) Bhattacharya, A.; Bhattacharya, S. Unraveling the role of vacancies in the potentially promising thermoelectric clathrates $\mathrm{Ba}_{8} \mathrm{Zn}_{x} \mathrm{Ge}_{46-x-y} \square_{y}$. Phys. Rev. B 2016, 94, 094305.

(54) Bhattacharya, S.; Levchenko, S. V.; Ghiringhelli, L. M.; Scheffler, M. Efficient ab initio schemes for finding thermodynamically stable and metastable atomic structures: Benchmark of cascade genetic algorithms. New Journal of Physics 2014, 16, 123016.

(55) Bhattacharya, A.; Bhattacharya, S. Exploring N-rich phases in $\mathrm{Li}_{x} \mathrm{~N}_{y}$ clusters for hydrogen storage at nanoscale. The Journal of Physical Chemistry Letters 2015, 6, 37263730. 
(56) Arora, E.; Saini, S.; Basera, P.; Kumar, M.; Singh, A.; Bhattacharya, S. Elucidating the role of temperature and pressure to the thermodynamic stability of charged defects in complex metal-hydrides: A case study of $\mathrm{NaAlH}_{4}$. The Journal of Physical Chemistry C 2019, 123, 62-69.

(57) Li, J.; Wei, S.-H.; Li, S.-S.; Xia, J.-B. Design of shallow acceptors in ZnO: Firstprinciples band-structure calculations. Phys. Rev. B 2006, 74, 081201.

(58) Ergönenc, Z.; Kim, B.; Liu, P.; Kresse, G.; Franchini, C. Converged GW quasiparticle energies for transition metal oxide perovskites. Phys. Rev. Materials 2018, 2, 024601.

(59) Cardona, M. Optical properties and band structure of $\mathrm{SrTiO}_{3}$ and $\mathrm{BaTiO}_{3}$. Phys. Rev. 1965, 140, A651-A655.

(60) Xu, Y.; Schoonen, M. A. A. The absolute energy positions of conduction and valence bands of selected semiconducting minerals. American Mineralogist 2000, 85, 543-556.

(61) Janotti, A.; Steiauf, D.; Van de Walle, C. G. Strain effects on the electronic structure of $\mathrm{SrTiO}_{3}$ : Toward high electron mobilities. Phys. Rev. B 2011, 84, 201304.

(62) Marques, M.; Teles, L. K.; Anjos, V.; Scolfaro, L. M. R.; Leite, J. R.; Freire, V. N.; Farias, G. A.; da Silva, E. F. Full-relativistic calculations of the $\mathrm{SrTiO}_{3}$ carrier effective masses and complex dielectric function. Applied Physics Letters 2003, 82, 3074-3076.

(63) Fadlallah, M.; Shibl, M. F.; Vlugt, T. J. H.; Schwingenschlögl, U. Theoretical study on cation codoped $\mathrm{SrTiO}_{3}$ photocatalysts for water splitting. J. Mater. Chem. A 2018, 6, $24342-24349$. 


\title{
Role of Defects in Photocatalytic Water Splitting: Monodoped vs Codoped $\mathrm{SrTiO}_{3}$
}

\author{
Manish Kumar," Pooja Basera, Shikha Saini, and Saswata Bhattacharya* \\ Department of Physics, Indian Institute of Technology Delhi, New Delhi, India \\ E-mail: manish.kumar@physics.iitd.ac.in[MK]; saswata@physics.iitd.ac.in[SB]
}

Phone: +91-11-2659 1359. Fax: +91-11-2658 2037 


\section{Supplemental Material}

I. Band gap of different codopants in $\mathrm{SrTiO}_{3}$ using PBE functional

II. Determination of chemical potential at different growth conditions.

III. Optimized structure of defected and pristine $\mathrm{SrTiO}_{3}$.

IV. Stability of defected $\mathrm{SrTiO}_{3}$ at different environmental growth conditions

V. Optical properties using HSE06 functional.

VI. Effect of functionals on phase diagrams.

VII. Dielectric constant $\left(\varepsilon_{\infty}\right)$ using $\mathrm{G}_{0} \mathrm{~W}_{0} @ \mathrm{HSE06}$ 


\section{Band gap of different codopants in $\mathrm{SrTiO}_{3}$ using $\mathrm{PBE}$ functional}

Note that the choice of $\mathrm{N} / \mathrm{Mn}$ is not fictitious. As a first step before choosing $\mathrm{N} / \mathrm{Mn}$, we did a careful prescreening of a large no. of various metals and nonmetals using $\mathrm{PBE}^{1}$ calculations. Even if PBE is not so good to estimate the band gap, it is good enough to give us some meaningful trend. The monodopants lead to the trap states that are detrimental to the photocatalysis. This has motivated us, to try different codopants and we have identified some of them (see the Table S1 and the no.s marked as red) to be promising for photocatalysis, where the band gap for maximum efficiency should be $\sim 2 \mathrm{eV}^{2,3}$ Note that in this class of oxide perovskite, the typical error in PBE band gap with respect to HSE06 ${ }^{4}$ is $\sim 1.0-1.5$ $\mathrm{eV}$ [for example, the pristine has the PBE (HSE06) band gap of $1.75(3.28) \mathrm{eV}$. Therefore, keeping this in mind we have identified few promising systems (marked as red) and one of them is the $\mathrm{N}$ and Mn codoped system. Incidentally, we have also noted that the individual monodopants (i.e. $\mathrm{N}$ and $\mathrm{Mn}$ ) are already experimentally synthesized. ${ }^{5-9}$ Hence, we have proposed, presumably for the first time, $\mathrm{N}$ and $\mathrm{Mn}$ as codopants. The band gap of all the considered codoped cases are given below in Table S1. 
Table S1: Band gap of different codopants in $\mathrm{SrTiO}_{3}$ using PBE functional

\begin{tabular}{|c|c|}
\hline Codoped System & Band gap (eV) \\
\hline $\mathrm{Cr}_{\mathrm{Ti}} \mathrm{B}_{\mathrm{O}}$ & 0.57 \\
$\mathrm{Cr}_{\mathrm{Ti}} \mathrm{C}_{\mathrm{O}}$ & metallic \\
$\mathrm{Cr}_{\mathrm{Ti}} \mathrm{F}_{\mathrm{O}}$ & 1.13 \\
$\mathrm{Cr}_{\mathrm{Ti}} \mathrm{N}_{\mathrm{O}}$ & 0.34 \\
$\mathrm{Cr}_{\mathrm{Ti}} \mathrm{S}_{\mathrm{O}}$ & 0.35 \\
$\mathrm{Fe}_{\mathrm{Ti}} \mathrm{B}_{\mathrm{O}}$ & 0.17 \\
$\mathrm{Fe}_{\mathrm{Ti}} \mathrm{C}_{\mathrm{O}}$ & metallic \\
$\mathrm{Fe}_{\mathrm{Ti}} \mathrm{F}_{\mathrm{O}}$ & 0.30 \\
$\mathrm{Fe}_{\mathrm{Ti}} \mathrm{N}_{\mathrm{O}}$ & metallic \\
$\mathrm{Fe}_{\mathrm{Ti}} \mathrm{S}_{\mathrm{O}}$ & metallic \\
$\mathrm{Mn}_{\mathrm{Ti}} \mathrm{B}_{\mathrm{O}}$ & 0.38 \\
$\mathrm{Mn}_{\mathrm{Ti}} \mathrm{C}_{\mathrm{O}}$ & 0.13 \\
$\mathrm{Mn}_{\mathrm{Ti}} \mathrm{F}_{\mathrm{O}}$ & 1.39 \\
$\mathrm{Mn}_{\mathrm{Ti}} \mathrm{N}_{\mathrm{O}}$ & 0.70 \\
$\mathrm{Mn}_{\mathrm{Ti}} \mathrm{S}_{\mathrm{O}}$ & 0.89 \\
$\mathrm{Rh}_{\mathrm{Ti}} \mathrm{B}_{\mathrm{O}}$ & 0.07 \\
$\mathrm{Rh}_{\mathrm{Ti}} \mathrm{C}_{\mathrm{O}}$ & 0.34 \\
$\mathrm{Rh}_{\mathrm{Ti}} \mathrm{F}_{\mathrm{O}}$ & 1.03 \\
$\mathrm{Rh}_{\mathrm{Ti}} \mathrm{N}_{\mathrm{O}}$ & 1.19 \\
$\mathrm{Rh}_{\mathrm{Ti}} \mathrm{S}_{\mathrm{O}}$ & 0.85 \\
$\mathrm{La}_{\mathrm{Sr}} \mathrm{B}_{\mathrm{O}}$ & 1.41 \\
$\mathrm{La}_{\mathrm{Sr}} \mathrm{C}_{\mathrm{O}}$ & 0.27 \\
$\mathrm{La}_{\mathrm{Sr}} \mathrm{F}_{\mathrm{O}}$ & 2.19 \\
$\mathrm{LaSr}_{\mathrm{Sr}} \mathrm{N}_{\mathrm{O}}$ & 1.42 \\
$\mathrm{La}_{\mathrm{Sr}} \mathrm{S}_{\mathrm{O}}$ & 1.43 \\
$\operatorname{Pr}_{\mathrm{Sr}} \mathrm{B}_{\mathrm{O}}$ & 1.33 \\
$\mathrm{Pr}_{\mathrm{Sr}} \mathrm{C}_{\mathrm{O}}$ & 1.65 \\
$\mathrm{Pr}_{\mathrm{Sr}} \mathrm{F}_{\mathrm{O}}$ & 2.06 \\
$\mathrm{Pr}_{\mathrm{Sr}} \mathrm{N}_{\mathrm{O}}$ & 1.25 \\
$\mathrm{Pr}_{\mathrm{Sr}} \mathrm{S}_{\mathrm{O}}$ & 1.47 \\
& \\
\hline
\end{tabular}

\section{Determination of chemical potential at different growth conditions}

The effect of temperature and pressure is explicitly taken into chemical potential term. The chemical potential $\Delta \mu_{\mathrm{O}}$ as a function of temperature $(T)$ and the partial pressure of oxygen 
$\left(p_{\mathrm{O}_{2}}\right)$ is calculated using the relation: ${ }^{10}$

$$
\begin{aligned}
\Delta \mu_{\mathrm{O}}\left(T, p_{\mathrm{O}_{2}}\right)= & \frac{1}{2}\left[-k_{\mathrm{B}} T \ln \left[\left(\frac{2 \pi m}{h^{2}}\right)^{\frac{3}{2}}\left(k_{\mathrm{B}} T\right)^{\frac{5}{2}}\right]\right. \\
& +k_{\mathrm{B}} T \ln p_{\mathrm{O}_{2}}-k_{\mathrm{B}} T \ln \left(\frac{8 \pi^{2} I_{A} k_{\mathrm{B}} T}{h^{2}}\right) \\
& +k_{\mathrm{B}} T \ln \left[1-\exp \left(\frac{-h \nu_{\mathrm{OO}}}{k_{\mathrm{B}} T}\right)\right] \\
& \left.-k_{\mathrm{B}} T \ln \mathcal{M}+k_{\mathrm{B}} T \ln \sigma\right]
\end{aligned}
$$

where $m$ is the mass, $I_{A}$ is the moment of inertia of $\mathrm{O}_{2}$ molecule, $\nu_{\mathrm{OO}}$ is the O-O stretching frequency, $\mathcal{M}$ is the spin multiplicity and $\sigma$ is the symmetry number.

Under equilibrium growth conditions, the chemical potentials are related to enthalpy of formation of $\mathrm{SrTiO}_{3}\left(\Delta \mathrm{H}_{\mathrm{f}}\left(\mathrm{SrTiO}_{3}\right)\right)$ by:

$$
\Delta \mu_{\mathrm{Sr}}+\Delta \mu_{\mathrm{Ti}}+3 \Delta \mu_{\mathrm{O}}=\Delta \mathrm{H}_{\mathrm{f}}\left(\mathrm{SrTiO}_{3}\right)
$$

To ensure the suppression of secondary phases, constraints are imposed on the different chemical potentials as given below:

$$
\begin{array}{r}
\Delta \mu_{\mathrm{Ti}}+2 \Delta \mu_{\mathrm{O}} \leq \Delta \mathrm{H}_{\mathrm{f}}\left(\mathrm{TiO}_{2}\right) \\
\Delta \mu_{\mathrm{Sr}}+\Delta \mu_{\mathrm{O}} \leq \Delta \mathrm{H}_{\mathrm{f}}(\mathrm{SrO}) \\
\Delta \mu_{\mathrm{X}} \leq 0 .
\end{array}
$$

We have calculated the formation energy in three regimes, viz. O-rich, O-intermediate and

Table S2: The chemical potentials at different environmental conditions

\begin{tabular}{lrrrrr}
\hline Growth Conditions & $\Delta \mu_{\mathrm{O}}$ & $\Delta \mu_{\mathrm{N}}$ & $\Delta \mu_{\mathrm{Ti}}$ & $\Delta \mu_{\mathrm{Sr}}$ & $\Delta \mu_{\mathrm{Mn}}$ \\
\hline O-poor (Ti-rich) & -4.55 & -1.48 & 0.00 & -3.98 & 0.00 \\
O-intermediate & -1.58 & -1.48 & -5.95 & -6.96 & -2.44 \\
O-rich (Ti-poor) & 0.00 & -1.48 & -9.11 & -8.54 & -5.61 \\
\hline
\end{tabular}

O-poor conditions. The $\Delta \mu_{\mathrm{X}}$ for different growth conditions are given in Table S2. Under 
O-rich and O-intermediate conditions, $\Delta \mu_{\mathrm{Ti}}$ and $\Delta \mu_{\mathrm{Mn}}$ are limited by the formation of $\mathrm{TiO}_{2}$ and $\mathrm{MnO}_{2}$, respectively. In O-intermediate condition, $\Delta \mu_{\mathrm{O}}$ takes the value to reflect the experimental growth condition $\left(T=1100{ }^{\circ} \mathrm{C}, p_{\mathrm{O}_{2}}=1 \mathrm{~atm}^{11}\right)$. Under O-poor (Ti-rich) condition, $\Delta \mu_{\mathrm{Ti}}$ and $\Delta \mu_{\mathrm{Mn}}$ are limited by the formation of metallic phase of $\mathrm{Ti}$ and $\mathrm{Mn}$, respectively. We have fixed the $\Delta \mu_{\mathrm{N}}=-1.48 \mathrm{eV}$, which is obtained at experimental growth condition. By knowing the stability of different dopants under certain conditions, one could deliberately dope the $\mathrm{SrTiO}_{3}$ in accordance with the need.

\section{Optimized structure of defected and pristine $\mathrm{SrTiO}_{3}$}
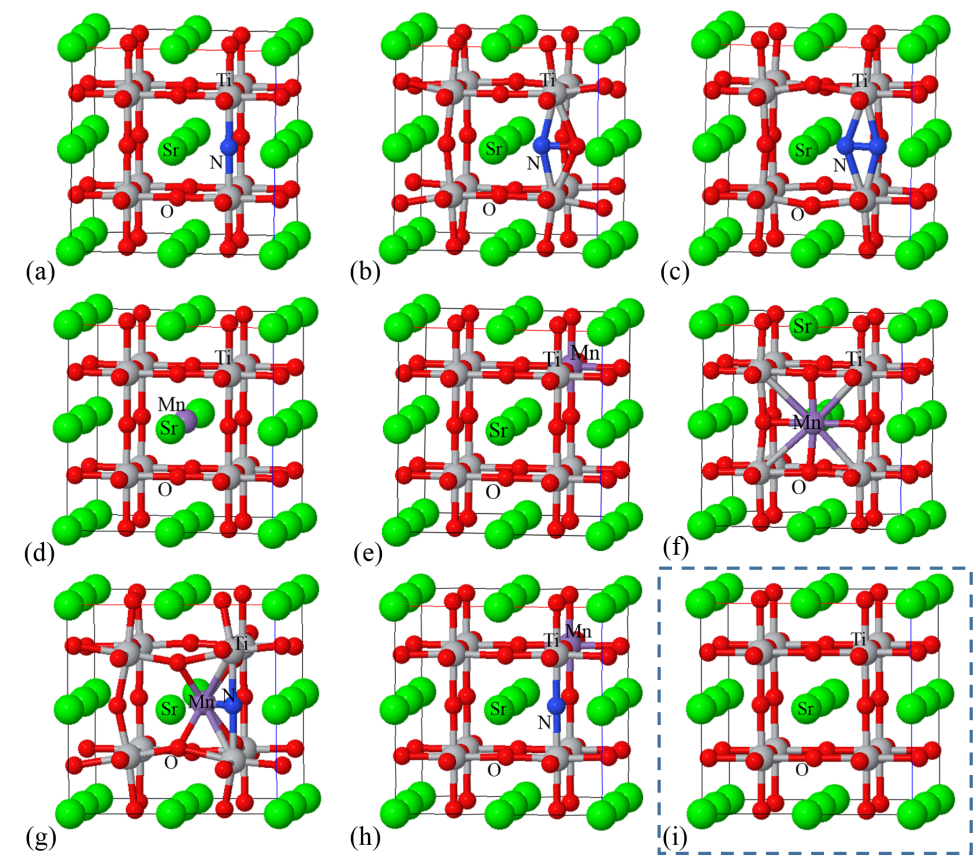

Figure S1: Ball and stick model of optimized structures of (a) $\mathrm{N}_{\mathrm{O}}$, (b) $\mathrm{N}_{\mathrm{i}}$, (c) $\left(\mathrm{N}_{2}\right)_{\mathrm{O}}$, (d) $\mathrm{Mn}_{\mathrm{Sr}}$, (e) $\mathrm{Mn}_{\mathrm{Ti}}$, (f) $\mathrm{Mn}_{\mathrm{i}}$ (g) $\mathrm{Mn}_{\mathrm{Sr}} \mathrm{N}_{\mathrm{O}}$, (h) $\mathrm{Mn}_{\mathrm{Ti}} \mathrm{N}_{\mathrm{O}}$, and (i) pristine $\mathrm{SrTiO}_{3}$. 


\section{Stability of defected $\mathrm{SrTiO}_{3}$ at different environ- mental growth conditions}

The formation energies of N-, Mn- and (N-Mn)-related defects as a function of $\mu_{\mathrm{e}}$ with different charge states, under different environmental conditions are shown in Figure S2, S3 and S4, respectively. Only those charge states of a particular defect are shown that have lowest formation energies.
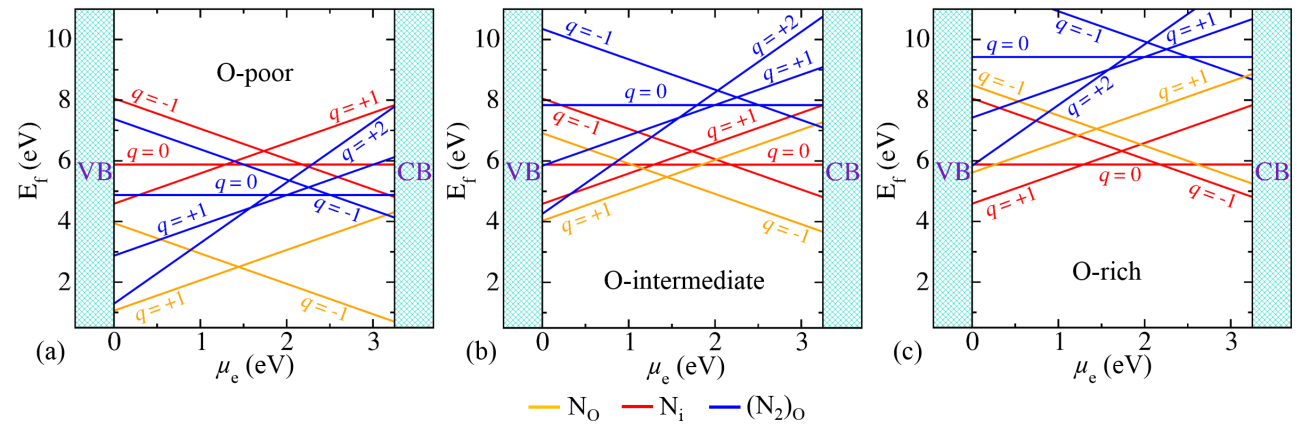

Figure S2: Formation energy of N-related defects as a function of chemical potential of electron under (a) O-poor, (b) O-intermediate and (c) O-rich condition.
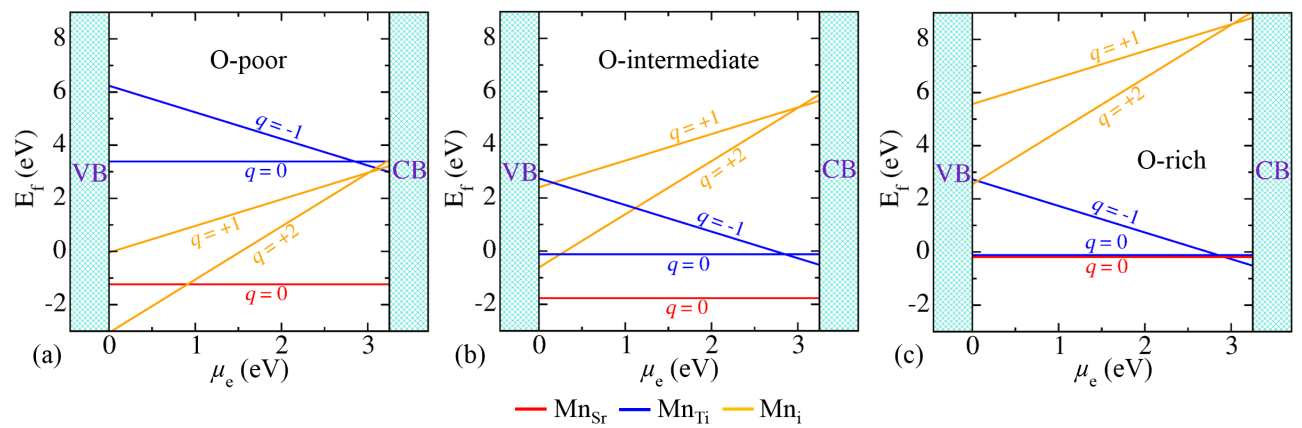

Figure S3: Formation energy of Mn-related defects as a function of chemical potential of electron under (a) O-poor, (b) O-intermediate and (c) O-rich condition. 

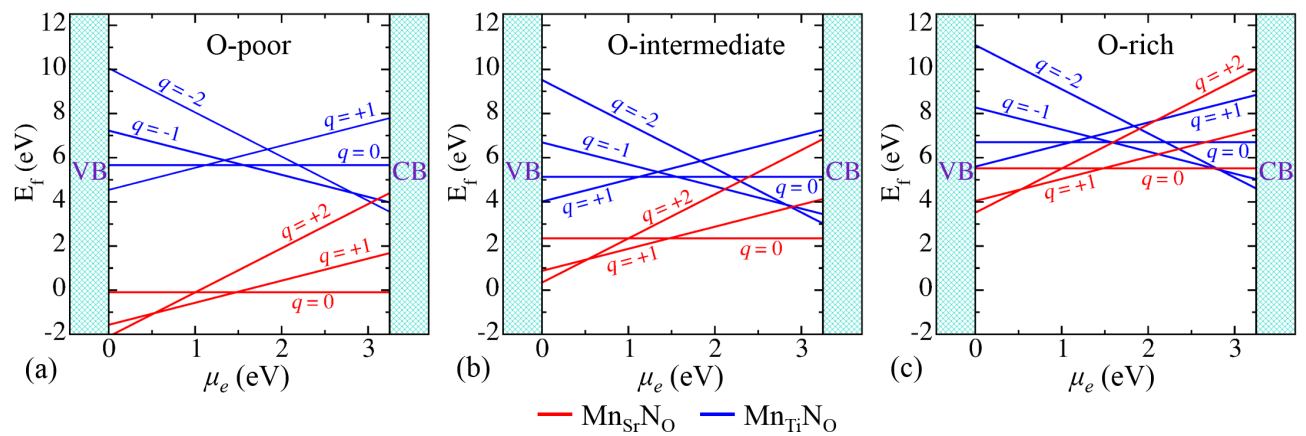

Figure S4: Formation energy of $(\mathrm{Mn}+\mathrm{N})$-related defects as a function of chemical potential of electron under (a) O-poor, (b) O-intermediate and (c) O-rich condition.

\section{Optical properties using HSE06 functional}

The real part $\epsilon_{1}(\omega)$ is calculated using the Kramers-Kronig transformation, and the imaginary part $\epsilon_{2}(\omega)$ is evaluated by taking summation over large number of empty states as implemented in VASP. The absorption coefficient $\alpha(\omega)$ is related to real and imaginary part of dielectric function as follow:

$$
\alpha(\omega)=\sqrt{2} \omega\left(\sqrt{\epsilon_{1}(\omega)^{2}+\epsilon_{2}(\omega)^{2}}-\epsilon_{1}(\omega)\right)^{\frac{1}{2}} .
$$

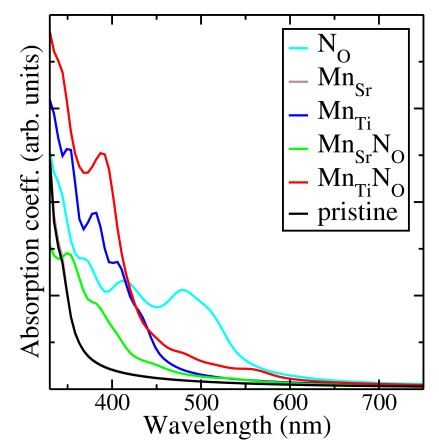

Figure S5: Absorption plot for undoped, monodoped and codoped $\mathrm{SrTiO}_{3}$ using HSE06 functional. 

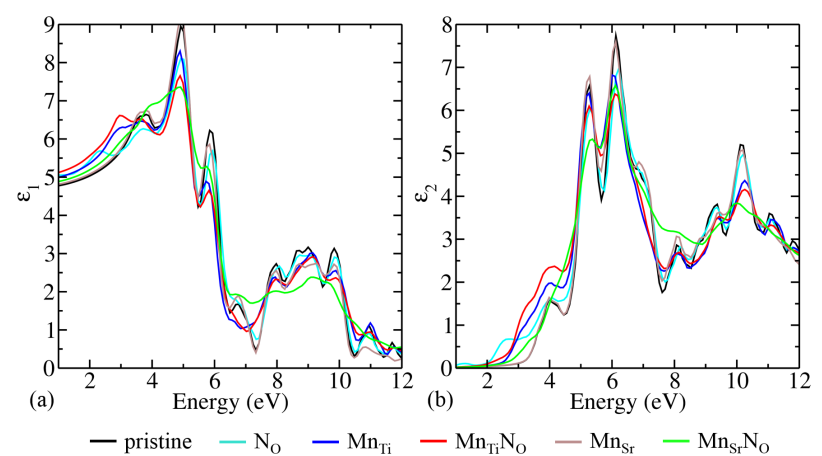

Figure S6: Spatially average (a) real $\left(\epsilon_{1}\right)$ and (b) imaginary $\left(\epsilon_{2}\right)$ part of the dielectric function obtained by HSE06 for the pristine, monodoped and codoped $\mathrm{SrTiO}_{3}$.

\section{Effect of functionals on phase diagrams}

We have benchmarked the exchange-correlation (xc) functionals viz. local-density approximation $\left(\mathrm{LDA}^{12}\right)$, semi-local generalized gradient approximation (PBE) and a more pronounced non-local hybrid functional HSE06 to ensure that our results are not an artifact of chosen treatment for the xc. The LDA and PBE functionals underestimate the band gap, giving a value of $1.37 \mathrm{eV}$ and $1.75 \mathrm{eV}$, respectively. While, the hybrid functional HSE06 reproduce the band gap of $3.28 \mathrm{eV}$ by taking the $28 \%$ of Hartree-Fock exact exchange into account, which is in nice match with the experimental value of $3.25 \mathrm{eV} .{ }^{13}$ We have also calculated the defect formation energy for single oxygen vacancy $\mathrm{E}_{\mathrm{f}}(\square)^{q}$ in our system with charge $q=0,+1,+2,-1$, and -2 using LDA, PBE and HSE06 functionals, since we have to find out the stability of defects as well as the other energetics. The $\mathrm{E}_{\mathrm{f}}(\square)^{q}$ has been calculated as follow: ${ }^{14-16}$

$$
\begin{aligned}
\mathrm{E}_{\mathrm{f}}(\square)^{q}= & \mathrm{E}_{\text {tot }}(\square)^{q}-\mathrm{E}_{\text {tot }}\left(\mathrm{SrTiO}_{3}\right)+\mu_{\mathrm{O}} \\
& +q\left(\mu_{\mathrm{e}}+\mathrm{VBM}+\Delta \mathrm{V}\right),
\end{aligned}
$$

where $\mathrm{E}_{\text {tot }}(\square)^{q}$ is the total energy of supercell containing single oxygen vacancy with charge state $q$, and $\mathrm{E}_{\text {tot }}\left(\mathrm{SrTiO}_{3}\right)$ is the total energy of the same supercell without any defect. $\mu_{\mathrm{O}}$ is 
the chemical potential of the oxygen atom, which is equal to the energy required to remove one $\mathrm{O}$ atom from the pristine supercell and put it into the $\mathrm{O}$ reservoir; $\mu_{\mathrm{O}}=\frac{1}{2} \mathrm{E}_{\text {tot }}\left(\mathrm{O}_{2}\right)$, and $\mathrm{E}_{\mathrm{tot}}\left(\mathrm{O}_{2}\right)$ is the total energy of isolated $\mathrm{O}_{2}$ molecule. $\mu_{\mathrm{e}}$ is the chemical potential of electron, that is referenced from VBM of the pristine supercell. $\Delta \mathrm{V}$ is the core level alignment between the supercells with and without defect.
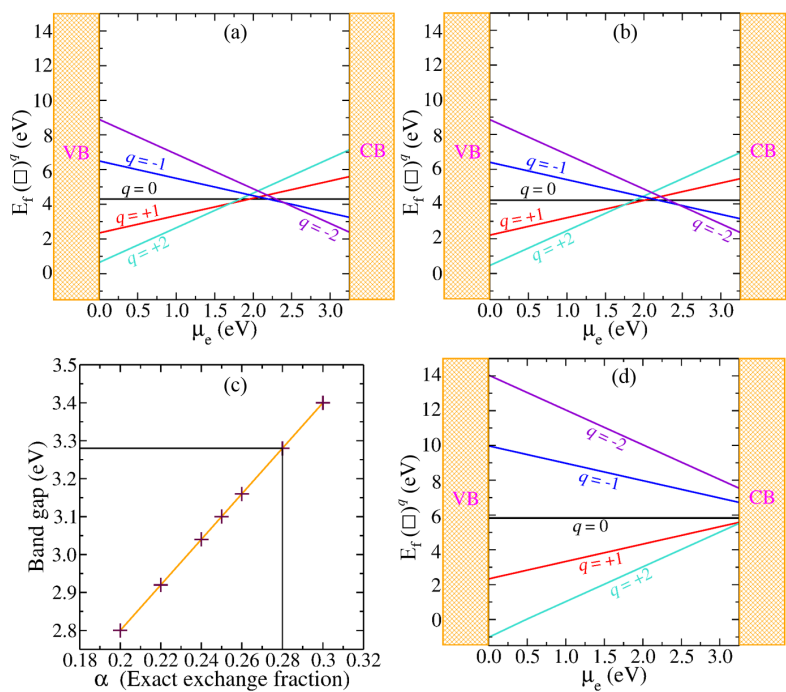

Figure S7: Formation energy of single oxygen vacancy defect as a function of chemical potential of electron under O-rich condition using (a) LDA, (b) PBE, and (d) HSE06 xc functional. (c) represents the variation of bandgap of pristine supercell as a function of exact exchange fraction contained in HSE06 functional.

We have found from Figure S7 that $q=+2$ and $q=-2$ are the stable charge states near VBM and CBm respectively using both LDA and PBE functionals. However, this is not the case with hybrid functional HSE06. With HSE06, we have observed that only $q=+2$ charge state is stable througout the band gap. It implies that, results which are obtained from LDA, PBE xc functionals are different from the HSE06 functional. And as a matter of fact, HSE06 functional is more accurate being non-local and containing a fraction of exact exchange, HSE06 xc functional is more reliable for our system. Therefore, we have done our further calculations with HSE06 functional. Note that we have used a 40-atom supercell to introduce defects in $\mathrm{SrTiO}_{3}$, which is a $2 \times 2 \times 2$ repetition of cubic $\mathrm{SrTiO}_{3}$ unit cell (5 
atoms). To ensure the convergence of supercell size, test calculations have been performed with 90 -atom supercell $\left(3 \times 3 \times 2\right.$ repetition of unit cell of $\left.\mathrm{SrTiO}_{3}\right)$ for the case of $\mathrm{N}_{\mathrm{O}}$ in order to ensure that the defect is fully localized. The results obtained from 40- and 90-atom supercells are consistent with each other. Therefore, we have performed all the calculations with 40-atom supercell.

\section{Dielectric constant $\left(\varepsilon_{\infty}\right)$ using $\mathbf{G}_{0} \mathbf{W}_{0} @ H S E 06$}

Table S3: The high frequency 'ion-clamped' dielectric constant $\left(\varepsilon_{\infty}\right)$

\begin{tabular}{ll}
\hline Configurations & $\varepsilon_{\infty}$ \\
\hline Pristine & 3.46 \\
$\mathrm{~N}_{\mathrm{O}}$ & 3.61 \\
$\mathrm{Mn}_{\mathrm{Sr}}$ & 3.48 \\
$\mathrm{Mn}_{\mathrm{Ti}}$ & 3.66 \\
$\mathrm{Mn}_{\mathrm{Sr}} \mathrm{N}_{\mathrm{O}}$ & 3.54 \\
$\mathrm{Mn}_{\mathrm{Ti}} \mathrm{N}_{\mathrm{O}}$ & 3.72 \\
\hline
\end{tabular}

\section{References}

(1) Perdew, J. P.; Burke, K.; Ernzerhof, M. Generalized gradient approximation made simple. Phys. Rev. Lett. 1996, 77, 3865.

(2) Walter, M. G.; Warren, E. L.; McKone, J. R.; Boettcher, S. W.; Mi, Q.; Santori, E. A.; Lewis, N. S. Solar water splitting cells. Chemical Reviews 2010, 110, 6446-6473.

(3) Stevanović, V.; Lany, S.; Ginley, D. S.; Tumas, W.; Zunger, A. Assessing capability of semiconductors to split water using ionization potentials and electron affinities only. Phys. Chem. Chem. Phys. 2014, 16, 3706-3714.

(4) Krukau, A. V.; Vydrov, O. A.; Izmaylov, A. F.; Scuseria, G. E. Influence of the exchange screening parameter on the performance of screened hybrid functionals. The Journal of Chemical Physics 2006, 125, 224106. 
(5) Mi, Y. Y.; Wang, S. J.; Chai, J. W.; Pan, J. S.; Huan, C. H. A.; Feng, Y. P.; Ong, C. K. Effect of nitrogen doping on optical properties and electronic structures of $\mathrm{SrTiO}_{3}$ films. Applied Physics Letters 2006, 89, 231922.

(6) Sun, T.; Lu, M. Modification of $\mathrm{SrTiO}_{3}$ surface by nitrogen ion bombardment for enhanced photocatalysis. Applied Surface Science 2013, 274, 176-180.

(7) Liu, C. M.; Zu, X. T.; Zhou, W. L. Photoluminescence of nitrogen doped $\mathrm{SrTiO}_{3}$. Journal of Physics D: Applied Physics 2007, 40, 7318-7322.

(8) Tkach, A.; Vilarinho, P. M.; Kholkin, A. L. Structure-microstructure-dielectric tunability relationship in Mn-doped strontium titanate ceramics. Acta Materialia 2005, 53, 50615069.

(9) Yang, H.; Kotula, P. G.; Sato, Y.; Chi, M.; Ikuhara, Y.; Browning, N. D. Segregation of $\mathrm{Mn}^{2+}$ dopants as interstitials in $\mathrm{SrTiO}_{3}$ grain boundaries. Materials Research Letters 2014, 2, 16-22.

(10) Bhattacharya, S.; Levchenko, S. V.; Ghiringhelli, L. M.; Scheffler, M. Efficient ab initio schemes for finding thermodynamically stable and metastable atomic structures: Benchmark of cascade genetic algorithms. New Journal of Physics 2014, 16, 123016.

(11) Wang, J.; Yin, S.; Komatsu, M.; Zhang, Q.; Saito, F.; Sato, T. Preparation and characterization of nitrogen doped $\mathrm{SrTiO}_{3}$ photocatalyst. Journal of Photochemistry and Photobiology A: Chemistry 2004, 165, 149-156.

(12) Perdew, J. P.; Wang, Y. Accurate and simple analytic representation of the electron-gas correlation energy. Phys. Rev. B 1992, 45, 13244.

(13) van Benthem, K.; Elsässer, C.; French, R. H. Bulk electronic structure of $\mathrm{SrTiO}_{3}$ : Experiment and theory. J. Appl. Phys. 2001, 90, 6156-6164. 
(14) Basera, P.; Saini, S.; Arora, E.; Singh, A.; Kumar, M.; Bhattacharya, S. Stability of non-metal dopants to tune the photo-absorption of $\mathrm{TiO}_{2}$ at realistic temperatures and oxygen partial pressures: A hybrid DFT study. Scientific reports 2019, 9, 1-13.

(15) Bhattacharya, A.; Bhattacharya, S. Unraveling the role of vacancies in the potentially promising thermoelectric clathrates $\mathrm{Ba}_{8} \mathrm{Zn}_{x} \mathrm{Ge}_{46-x-y} \square_{y}$. Phys. Rev. B 2016, 94, 094305.

(16) Bhattacharya, S.; Berger, D.; Reuter, K.; Ghiringhelli, L. M.; Levchenko, S. V. Theoretical evidence for unexpected O-rich phases at corners of $\mathrm{MgO}$ surfaces. Phys. Rev. Materials 2017, 1, 071601. 